\title{
Effect of differences in coefficient of thermal expansion of veneer and Y-TZP ceramics on interface phase transformation
}

\author{
Journal Article \\ Author(s): \\ Hallmann, Lubica; Ulmer, Peter; Wille, Sebastian; Kern, Matthias \\ Publication date: \\ 2014-09 \\ Permanent link: \\ https://doi.org/10.3929/ethz-a-010345344
}

Rights / license:

In Copyright - Non-Commercial Use Permitted

Originally published in:

Journal of prosthetic dentistry 112(3), https://doi.org/10.1016/j.prosdent.2013.11.009 


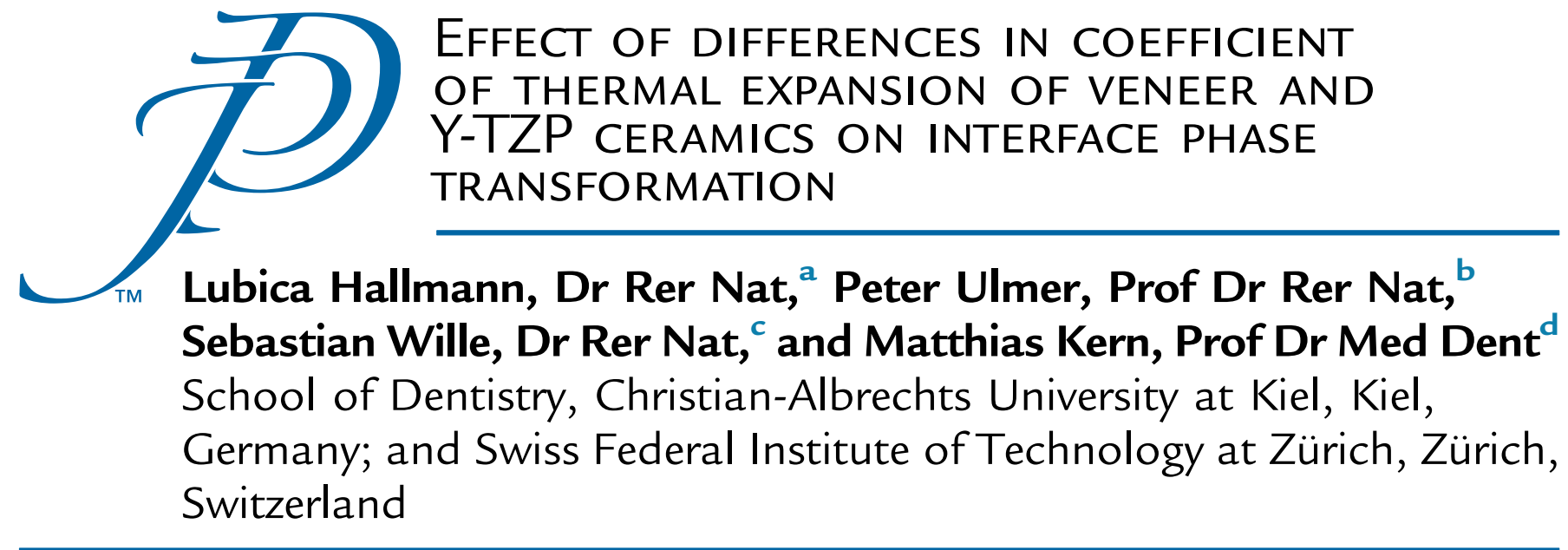

Statement of problem. The stability of veneering ceramics requires further investigation.

Purpose. The purpose of this study was to investigate, with Raman spectroscopy, the occurrence and extent of the tetragonal to monoclinic phase transformation in yttria partially stabilized tetragonal polycrystalline zirconia (Y-TZP) ceramic at the veneer-framework interface.

Materials and methods. Three different Y-TZP blanks Cercon base, ZENO TEC, and Zerion were used. The specimens were sintered according to the recommendations of the manufacturers $\left(1350^{\circ} \mathrm{C}\right.$ Cercon base, $1450^{\circ} \mathrm{C} Z \mathrm{ZNO} \mathrm{TEC}$, and $1500^{\circ} \mathrm{C}$ Zerion for 2 hours). Three veneer ceramics with different coefficients of thermal expansion, Cercon ceram kiss, Zirox, and VITA VM9 were used to veneer the Y-TZP frameworks. For the investigation of the temperature gradient on the phase transformation of Y-TZP ceramic, some specimens were fractured, with a universal testing machine along the long axis of the coping.

Results. No evidence was found for the presence of the tetragonal to monoclinic phase transformation for nonabraded and nonveneered specimens. The tetragonal to monoclinic phase transformation was observed at the veneer-framework interface for all veneered specimens and was dependent on the sintering temperature of the framework. The highest volume fractions of the monoclinic phase at the veneer-framework interface amounted to 0.57 (Cercon base), 0.69 (ZENO TEC), and 0.72 for the Zerion framework. The tetragonal to monoclinic phase transformation was not homogenous along the veneerframework interface and depended on the distance from the cross section of the veneer-framework interface. The greatest tetragonal to monoclinic transformation was observed at the interface and disappeared with increasing distance from it. For the veneered Cercon base specimens, the volume fraction of the monoclinic phase decreased from 0.53 to 0.13 over a distance of $20 \mu \mathrm{m}$. No phase transformation was observed at a distance that exceeded $20 \mu \mathrm{m}$ from the cross section of the veneer-framework interface.

Conclusion. This study demonstrated that the firing process of veneer ceramic and the difference in the coefficients of thermal expansion between the ceramic framework and the veneer ceramic significantly influenced the stability of the tetragonal phase of Y-TZP ceramic at the veneer-framework interface. (J Prosthet Dent 2014

\section{Clinical IMPLICATIONS}

The stresses created along the veneer-zirconia framework interface during the veneering process are responsible for the tetragonal to monoclinic phase transformation of zirconia. This transformation is accompanied by a localized increase in zirconia volume at the veneer-zirconia framework interface and may influence the stability of the veneer.

\footnotetext{
${ }^{a}$ Research Associate, Department of Prosthodontics, Propaedeutics and Dental Materials, School of Dentistry, Christian-Albrechts University at Kiel.

${ }^{\mathrm{b}}$ Professor and Chair, Department of Igneous Petrology, Swiss Federal Institute of Technology at Zürich.

${ }^{c}$ Research Associate, Department of Prosthodontics, Propaedeutics and Dental Materials, School of Dentistry, Christian-Albrechts University at Kiel.

${ }^{\mathrm{d}}$ Professor and Chair, Department of Prosthodontics, Propaedeutics and Dental Materials, School of Dentistry, Christian-Albrechts University at Kiel.
} 
Zirconia-based ceramics have attracted the attention of researchers because of their high biocompatibility, high flexural strength, and toughness. The development of computer-aided design/computer-assisted manufacturing (CAD/CAM) technologies has enabled the production of complete and partial coverage crowns and partial fixed dental prostheses from high-strength zirconia. ${ }^{1-7}$ Zirconia ceramic occurs in 3 modifications: the monoclinic $(\mathrm{m})$ phase (stable up to $1170^{\circ} \mathrm{C}$ ), the tetragonal ( $\mathrm{t}$ ) phase (stable up to $2370^{\circ} \mathrm{C}$ ), and the cubic (c) phase (stable up to $2680^{\circ} \mathrm{C}$ ). The $\mathrm{c}$ phase has moderate mechanical properties, the $\mathrm{m}$ phase shows reduced mechanical performance and is less dense than the other modifications of zirconia, and the $t$ phase provides superior mechanical properties. $^{1,6,8}$ In the dental industry, yttria partially stabilized t polycrystalline zirconia (Y-TZP) ceramic is commonly used. The $t \rightarrow m$ phase transformation of Y-TZP, which occurs through a martensitic diffusionless shear process can be induced by externally applied stress and is associated with a volume increase of up to $5 \% .^{1,6,8-11}$ The compressive stresses that are induced during this transformation oppose the propagation of cracks, thereby positively affecting the mechanical properties of zirconia-based ceramics. A more extensive $t \rightarrow m$ phase transformation has a catastrophic effect on the mechanical properties of zirconia ceramics. ${ }^{6}$

Most dental ceramic restorations are composed of 2 layers of materials, the ceramic framework to carry the load and the veneer porcelain for the esthetics. Veneers used with zirconia frameworks are primarily composed of glass ceramics with minor compositional and microstructural differences, depending on the manufacturer. Kaoline, silica, and feldspar are the main components of veneering ceramics. Leucite-reinforced glass ceramics and the nanofluorapatite glass ceramics are used to fabricate zirconia restorations. ${ }^{12}$ The fabrication of crowns and partial fixed dental prostheses involves a series of thermal treatments. The matching of the thermal expansion between the veneer and ceramic framework is critical for the avoidance of cracking after firing. ${ }^{12-22}$ DeHoff et $\mathrm{al}^{13}$ outlined the dependence of the residual stresses on the coefficient of thermal expansion and the geometries of the specimens. In addition, the residual stress is dependent on the thermal conductivities of the materials due to a buildup of thermal gradients during cooling. Zirconia has a low thermal expansion, but its low thermal diffusivity results in a high tensile residual stress at the interface with the veneer. ${ }^{12-22}$ Tholey et $\mathrm{al}^{23}$ detected the occurrence of the $t \rightarrow m$ phase transformation at the stress interface and explained it by the presence of the liquid used to fabricate the veneering ceramics.

The aim of this study was to investigate, by using Raman spectroscopy, the occurrence and extent of the phase transformation in Y-TZP ceramic at the veneer-framework interface. ${ }^{24-30}$ The working hypothesis was that the buildup of the residual stresses at this interface during the firing procedures for the preparation of veneering ceramic is responsible for the stress-induced martensitic diffusionless $\mathrm{t} \rightarrow \mathrm{m}$ phase transformation at the veneer-framework interface.

\section{MATERIAL AND METHODS}

In this study, Y-TZPs (zirconia 5 wt\% $\mathrm{Y}_{2} \mathrm{O}_{3}, \quad<2 \quad w t \% \quad \mathrm{HfO}_{2}, \quad<1 \quad w t \%$ $\mathrm{Al}_{2} \mathrm{O}_{3}+\mathrm{SiO}_{2}$ ) from 3 manufacturers
(Cercon base [CB], DeguDent GmbH; ZENO TEC [ZT], Wieland+Dental; and Zerion [Ze], Straumann) were used as a framework material. Zirconia blanks (CB) were milled with a Cercon brain (DeguDent) CAM machine. Other blanks (ZT and Ze) were milled with a CAD/CAM (CAD [Cerec; MC XL]; CAM [InLab Sirona]) device. For each type of Y-TZP, 18 copings were divided into 6 groups: nontreated coping as the control group; airborne-particle-abraded coping; airborne-particle abraded and veneered coping; fractured coping; fractured and airborne-particle abraded coping; and fractured, airborneparticle abraded and veneered coping $(n=3)$ (Table I). The sintering of frameworks was performed according to the instructions of the manufacturers (CB, ZT, and Ze were sintered at $1350^{\circ} \mathrm{C}, 1450^{\circ} \mathrm{C}$, and $1500^{\circ} \mathrm{C}$, respectively, for 2 hours). The veneering surfaces of the frameworks, according to the instructions of the manufacturer (DeguDent), were abraded with abrasive $110-\mu \mathrm{m}$ alumina particles at a pressure of $0.3 \mathrm{MPa}$ and at a distance of $10 \mathrm{~mm}$ (CEMAT NT4; Wassermann); the same conditions (to avoid the influence of airborne-particle pressure) were applied for the other Y-TZP copings. After airborne-particle abrasion treatments, all the specimens were air cleaned at a pressure of $0.25 \mathrm{MPa}$ for 1 minute. Cercon ceram kiss veneering material (DeguDent) was

TABLE I. Preparation and grouping of specimens $(n=3)$

\section{Groups (3 specimens \\ prepared per Y-TZP) Specimens}

1

2

3

4

5
Control coping (sintered): CB-1, ZT-1, Ze-1

airborne-particle abraded coping: CB-2, ZT-2, Ze-2

airborne-particle abraded and veneered coping: CB-3, ZT-3, Ze-3

Fractured coping: CB-4, ZT-4, Ze-4

Fractured and airborne-particle abraded coping: CB-5, ZT-5, Ze-5

Fractured, airborne-particle abraded, and veneered coping: CB-6, ZT-6, Ze-6

Y-TZP, yttria partially stabilized tetragonal polycrystalline zirconia; CB, Cercon base; ZT, ZENO TEC; Ze, Zerion. 
used for CB frameworks, Zirox (Wieland+Dental) was used for the ZT frameworks and VITA VM9 (Vita frameworks (Table II). The CTEs of specimens used in this study were zirconia $=10.5 \times 10^{-6} \mathrm{~K}^{-1}$, Cercon ceram Kiss $=9.2 \times 10^{-6} \mathrm{~K}^{-1}, \quad$ VITA VM9 $=8.8$ $9.2 \times 10^{-6} \mathrm{~K}^{-1}$, and Zirox $=9.3 \times 10^{-6} \mathrm{~K}^{-1}$.

Five veneer layers were used for the preparation of each veneering ceramic. The coated framework was fired at the proper temperature according to the instructions of the manufacturers (Table III). The firing processes were performed in a calibrated oven

TABLE II. Qualitative chemical composition of veneering ceramics used in this study

\begin{tabular}{|c|c|c|c|}
\hline \multirow{2}{*}{$\begin{array}{l}\text { Veneering } \\
\text { Ceramic }\end{array}$} & \multicolumn{3}{|c|}{ Batch } \\
\hline & Chemical Composition & No. & Manufacturers \\
\hline Cercon base kiss & $\begin{array}{c}\mathrm{SiO}{ }_{2}, \mathrm{Al}_{2} \mathrm{O}_{3}, \mathrm{~K} 2 \mathrm{O}, \mathrm{Na}_{2} \mathrm{O}, \mathrm{BaO}, \mathrm{B}_{2} \mathrm{O}_{3} \\
\mathrm{CaO}, \mathrm{CeO}_{2}, \mathrm{Li}_{2} \mathrm{O}, \mathrm{P}_{2} \mathrm{O}_{3}, \mathrm{SnO}_{2} \\
\mathrm{TiO}_{2}, \mathrm{Y}_{2} \mathrm{O}_{3}, \mathrm{ZrO}_{2}, \mathrm{ZnO}, \text { pigments }\end{array}$ & 130055 & DeguDent \\
\hline Zirox & $\begin{array}{c}\mathrm{SiO}_{2}, \mathrm{Al}_{2} \mathrm{O}_{3}, \mathrm{~K}_{2} \mathrm{O}, \mathrm{Na}_{2} \mathrm{O}, \mathrm{TiO}_{2}, \mathrm{ZrO}_{2} \\
\mathrm{CaO}, \mathrm{B}_{2} \mathrm{O}_{3}, \mathrm{~F}, \mathrm{Li}_{2} \mathrm{O} \text {, pigments }\end{array}$ & $3 / 06$ & Wieland+Denta \\
\hline VITA VM9 & $\begin{array}{c}\mathrm{SiO}_{2}, \mathrm{Al}_{2} \mathrm{O}_{3}, \mathrm{~K} \mathrm{~K}_{2} \mathrm{O} \mathrm{Na}_{2} \mathrm{O}, \mathrm{TiO}_{2}, \mathrm{CeO}_{2} \\
\mathrm{ZrO}_{2}, \mathrm{CaO}, \mathrm{SnO}_{2}, \mathrm{P}_{2} \mathrm{O}_{5}, \mathrm{MgO} \\
\mathrm{FeO}, \mathrm{B}_{2} \mathrm{O}_{3}, \text { pigments }\end{array}$ & 30250 & Vita Zahnfabrik \\
\hline
\end{tabular}

(Austromat M; Dekema). The powder of each veneer was mixed with the liquid provided by the manufacturers and was applied on the surface of the framework. This step was repeated after applying each veneer layer. The thicknesses of the frameworks and veneer layers were approximately $0.5 \mathrm{~mm}$ and $1 \mathrm{~mm}$. A number of factors influence the martensitic stress-induced $\mathrm{t} \rightarrow \mathrm{m}$ phase transformation of Y-TZP ceramic, including the thickness of the veneer ceramic. ${ }^{31-35}$ This aspect, however, was not the principal target of this exploratory study that focused on the evaluation of the Raman method for the Zahnfabrik) was used for the Ze

TABLE III. Firing schedules of veneering ceramics according to manufacturers

\begin{tabular}{|c|c|c|c|c|c|c|}
\hline \multirow{2}{*}{\multicolumn{2}{|c|}{$\begin{array}{l}\text { Veneering } \\
\text { Ceramic }\end{array}$}} & \multicolumn{2}{|c|}{ Predrying } & \multirow{3}{*}{$\begin{array}{c}\text { Heating } \\
\text { Rate }\left({ }^{\circ} \mathrm{C} / \mathrm{min}\right) \\
55\end{array}$} & \multirow{3}{*}{$\begin{array}{c}\text { Firing } \\
\text { Temperature }\left({ }^{\circ} \mathbf{C}\right) \\
970\end{array}$} & \multirow{3}{*}{$\begin{array}{c}\text { Holding } \\
\text { Time (min) } \\
1\end{array}$} \\
\hline & & \multirow{2}{*}{$\frac{\text { Temperature }\left({ }^{\circ} \mathrm{C}\right)}{575}$} & \multirow{2}{*}{$\frac{\text { Time }(\mathbf{m i n})}{8}$} & & & \\
\hline Ceram Kiss & Liner 1 & & & & & \\
\hline & Liner 2 & 575 & 8 & 55 & 960 & 1 \\
\hline & Shoulder 1 & 450 & 6 & 55 & 850 & 1 \\
\hline & Dentin 1 & 450 & 5 & 55 & 830 & 1 \\
\hline & Glaze & 450 & 3 & 55 & 800 & 1 \\
\hline Zirox & Shoulder 1 & 575 & 8 & 45 & 980 & 1 \\
\hline & Shoulder 1 & 575 & 8 & 45 & 960 & 1 \\
\hline & Liner & 575 & 8 & 45 & 930 & 1 \\
\hline & Dentin & 575 & 9 & 45 & 900 & 2 \\
\hline & Glaze & 575 & 5 & 45 & 880 & 1 \\
\hline Vita M9 & Shoulder 1 & 500 & 6 & 80 & 980 & 1 \\
\hline & Shoulder 2 & 500 & 6 & 80 & 980 & 1 \\
\hline & Liner & 500 & 6 & 55 & 930 & 1 \\
\hline & Dentin & 500 & 6 & 55 & 910 & 2 \\
\hline & Glaze & 500 & - & 80 & 900 & 1 \\
\hline
\end{tabular}

investigation of this phase transformation at the veneer-framework interface.

To determine the occurrence and extent of the $t \rightarrow m$ phase transformation that resulted from the temperature gradients at the veneer-framework interface, the specimens were loaded with a universal testing machine (Zwick). The load was applied with a flat device on the incisal edge parallel to the long axis of the crown. The force was applied at a crosshead speed of 1 $\mathrm{mm} / \mathrm{min}$ until failure. To ensure a uniform force distribution, a $0.5-\mathrm{mm}$ tin foil (Dentaurum) was placed between the incisal edge and the loading device. The universal testing machine was used to preserve the same conditions for the preparation of all specimens.

\section{Phase transformation}

A confocal Raman microscope (CRM 200; WITec GmbH) equipped with a helium-cadmium ( $\mathrm{HeCd}$ ) laser with a wavelength of $532 \mathrm{~nm}$ was used to detect the $t \rightarrow m$ phase transformation. The microscope was operated in the backscattering mode with 
a $\times 100$ objective and a lens numerical aperture, NA, of 0.9. The lateral resolution $\Delta X_{\text {lateral }}$ of the microscope defined by the Rayleigh equation (according to the manufacturer)

$$
\Delta X_{\text {lateral }} \approx 1.22 \frac{\lambda \text { laser }}{2 \times N A}
$$

is $360 \mathrm{~nm}$.

The calculation of depth resolution defined by the following equation (according to the manufacturer)

$$
\Delta x_{a x i a l} \approx 1.4 \times n^{2} \frac{\lambda \text { laser }}{(N A)^{2}}
$$

is $920 \mathrm{~nm}$.

Raman spectra were acquired with a spectrometer equipped with a chargecoupled device. The size of the detector was $1024 \times 127$ pixels (pixels per line $\times$ pixels per column). A holographic grating of 900 grooves $/ \mathrm{mm}$ was used to disperse the wave reflected from the specimens. The size of the pinhole was $100 \mu \mathrm{m}$.

Reference spectra were acquired on the sintered and the airborne-particleabraded Y-TZP frameworks. An area of interest of $10 \times 10 \mu \mathrm{m}$ at the veneerframework interface was selected. Images (20 lines per image and 20 points per line) were acquired with a 0.52 second integration time and a $\times 100$ objective. The line scan $(\times 100$ objective), which was perpendicular to the veneer-framework interface, was recorded on the selected area. The distance between the 2 measured points was 0.52 $\mu \mathrm{m}$. The image sampling volume resolution was $0.25 \mu \mathrm{m}^{3}$. The distance between the 2 measurements was $1 \mathrm{~mm}$ for fractured specimens and $2 \mathrm{~mm}$ for nonfractured specimens $(n=10)$. For the preparation of fractured specimens, the measurements were performed only at the site of the coping where no load was applied. The dependence of the phase transformation of the framework on the distance from the cross section at the veneer-framework interface was investigated in an area of interest of $20 \times 20 \mu \mathrm{m}$ at the veneer-framework interface (which corresponded to an area where the phase transformation was found in the previous measurement). Images (20 lines per image and 20 points per line) were acquired with a 2 -second integration time and a $\times 100$ objective. The distance between the 2 points was $1.05 \mu \mathrm{m}$, and the probe volume resolution was 1.2 $\mu \mathrm{m}^{2}$. The $\mathrm{m}$ volume fraction was calculated by using the following equation ${ }^{36}$ :

$V m=\frac{I m_{178 \mathrm{~cm}^{-1}}+I m_{189 \mathrm{~cm}^{-1}}}{0.33\left(I t_{145 \mathrm{~cm}^{-1}}+I t_{256 \mathrm{~cm}^{-1}}\right)+\left(I m_{178 \mathrm{~cm}^{-1}}+I m_{189 \mathrm{~cm}^{-1}}\right)}$

The Raman spectra were fitted with software (PeakFit v4.12; Seasolve Software) for the calculation of $\mathrm{Vm}$. The fitting procedure was performed by using a Lorentzian curve on a linear background. The calculation of $\mathrm{Vm}$ was performed by using the areas of the $t$ peaks at 145 and $265 \mathrm{~cm}^{-1}$ and the $\mathrm{m}$ doublet between 178 and $190 \mathrm{~cm}^{-1}$. A 1-way ANOVA and a post hoc Scheffé test $(\alpha=.05)$ were used to statistically analyze the results.

\section{RESULTS}

Raman images of a selected fractured coping, veneer (Cercon ceram kiss)-framework (CB) and Raman spectra acquired on the veneer surface at the veneer-framework interface and on the Y-TZP surface are displayed in Figure 1. Major peaks in the Raman spectra were detected at $149,177,190$, $262,324,334,344,463,477,609$, and $640 \mathrm{~cm}^{-1}$; additional weak peaks appeared at 212, 221, 378, and $534 \mathrm{~cm}^{-1}$. Raman peaks at 149,262 , 324, 463, 609, and $640 \mathrm{~cm}^{-1}$ were assigned to the Raman active modes of the $t$ phase of Y-TZP ceramic (Table IV). The peaks at 180, 190, 334, and 477 $\mathrm{cm}^{-1}$ were assigned to the Raman active modes of the $m$ phase of zirconia. Only a single peak at $466 \mathrm{~cm}^{-1}$ was observed for the veneering ceramic. The intensity of $\mathrm{m}$ bands at 180 to $190 \mathrm{~cm}^{-1}$ depended on the distance from the interface. With increasing distance from the veneer-framework interface, the intensity of these peaks decreased (Figs. 1, 2A). Lower $\mathrm{m}$ volume fractions were obtained up to a distance of $20 \mu \mathrm{m}$ from the cross section of the veneer-framework interface. The $\mathrm{m}$ volume fractions were $0.49,0.42,0.24$, and 0.13 for the points 2 to 5 , respectively (the distance between 2 points was $4 \mu \mathrm{m}$ ) (Figs. 1, 2A). Identical trends were observed for other copings. As shown in Figures 1 and $2 \mathrm{~B}$, the $t \rightarrow m$ phase transformation was not homogeneous because the intensity of the $m$ peaks in the region of 180 to 190 $\mathrm{cm}^{-1}$ changed according to the location of the measured spots. The $\mathrm{m}$ volume fractions were $0.33,0.51,0.35,0.40$, $0.37,0.51$, and 0.27 for spots 1 to 7 , respectively (Figs. 1, 2B). The dependence of Raman peak intensities and positions on the treatments of the frameworks is shown in Figure 2. No evidence was found for the presence of $\mathrm{m}$ peaks for nonfractured and fractured specimens (Fig. 2 and Table $V$, spectra CB-1, CB-4, ZT-1, ZT-4, Ze-1, and Ze-4). For airborne-particle-abraded specimens (spectra CB-2, CB-5, ZT-2, ZT-5, Ze-2, and Ze-5), a broad peak was observed in the region of 170 to $190 \mathrm{~cm}^{-1}$. The peaks at 320 and 464 $\mathrm{cm}^{-1}$ assigned to the $\mathrm{t}$ phase were broader than those of the nonabraded specimens, which can be attributed to the appearance of $\mathrm{m}$ peaks at 342 and $478 \mathrm{~cm}^{-1}$. For the veneered specimens (spectra CB-3, CB-6, ZT-3, ZT-6, Ze-3, and $\mathrm{Ze}-6)$, the intensities of the peaks of the m phase at 180 to $192 \mathrm{~cm}^{-1}$ and $478 \mathrm{~cm}^{-1}$ increased considerably. The intensity of $\mathrm{m}$ peaks at 180 to 190 , 385 , and $477 \mathrm{~cm}^{-1}$ increased for the veneer-framework interface of coping compared with the airborne-particle abraded coping. The broadening and the changes in intensity of the peaks in the regions 464 to $478 \mathrm{~cm}^{-1}$ and 600 to $700 \mathrm{~cm}^{-1}$ were observed when the $t \rightarrow m$ phase transformation occurred. The intensity of peaks at 464 to $477 \mathrm{~cm}^{-1}$ in comparison with the intensity of the peaks at $644 \mathrm{~cm}^{-1}$ increased for the specimens where the phase transformation occurred. The peak at $644 \mathrm{~cm}^{-1}$ was rather broad for all veneered specimens, because the $\mathrm{c}$ and $\mathrm{m}$ modifications of zirconia also have Raman active modes in this spectral domain (Table IV). Detecting 

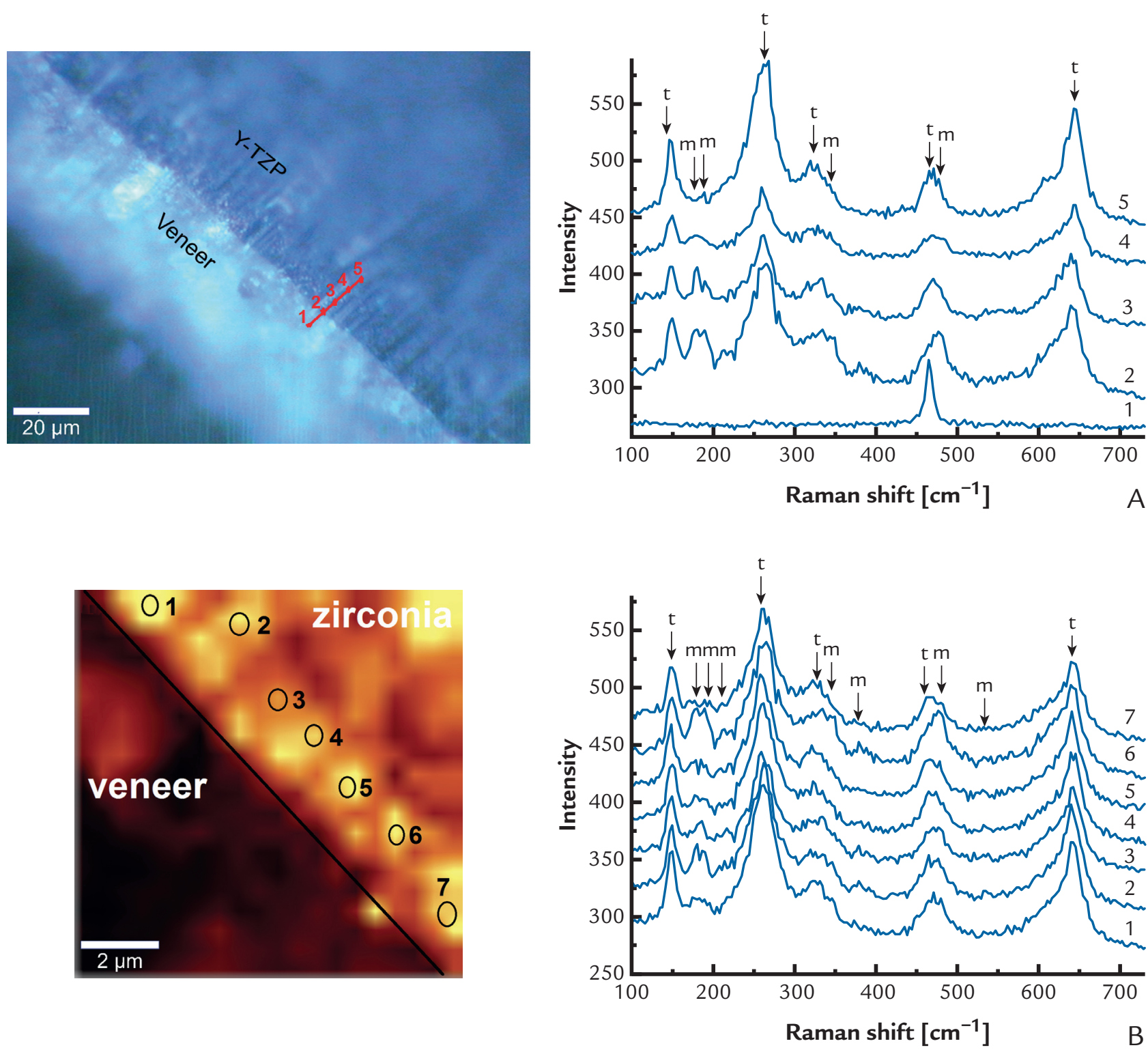

Photomicrographs and Raman spectra of fractured coping, Cercon base, and Cercon ceram kiss were used as framework and veneer (group 6). A, Photographic image made with optical microscope of Raman spectrometer, numbers ( 1 to 5 ) indicate points where spectra were recorded. B, Selected area of $10 \mu \mathrm{m} \times 10 \mu \mathrm{m}$.

the $c$ phase in these specimens is difficult because this phase has only 1 active Raman mode, $F_{2 \mathrm{~g}}$ at $616 \mathrm{~cm}^{-1}$. Minor peaks observed at 105,352 , 507,566 , and $582 \mathrm{~cm}^{-1}$ for all veneered specimens were assigned to the $\mathrm{m}$ phase (Fig. 2). The $m$ volume fraction $(\mathrm{Vm})$ of all specimens is given in Table IV. The Raman measurements were performed on 10 different areas for each group. The highest $t \rightarrow m$ phase transformation at the veneerframework was observed for the specimens of groups 3 and 6 (Table V). Two or 3 of the measured areas of these groups showed the highest intensities of $m$ peaks in the region of 180 to $190 \mathrm{~cm}^{-1}$. No significant difference was observed $(P>.05)$.

\section{DISCUSSION}

The results indicate that, before the veneering procedure, the nonfractured and fractured surfaces of Y-TZP ceramics consisted only of the $t$ phase. After airborne-particle abrasion, the stress-induced martensitic $t \rightarrow m$ phase transformation developed. The intensities of the Raman peaks assigned to the $\mathrm{m}$ phase increased at the veneer-framework interface in airborne-particle abraded specimens, and the broadening of the $t$ phase peaks could be indexed as a strained structure. Finite element calculations by DeHoff et $\mathrm{al}^{13}$ suggest that, within the first 5 minutes of the cooling process, the transient stresses are higher than the residual values. The researchers related the buildup of stress to negative or positive mismatch between the thermal expansion coefficients of the veneer and framework. Zhang et $\mathrm{al}^{34}$ calculated the residual stresses at the veneer-core interface. According to these researchers, no stresses were detected for temperatures above the 
TABLE IV. Raman shift $\left(\mathrm{cm}^{-1}\right)$ of zirconia modifications

\section{Monoclinic phase}

\begin{tabular}{cccccccc}
\hline This study & Ref $^{30}$ & Ref $^{42}$ & Ref $^{48}$ & Ref $^{49}$ & Ref $^{50}$ & Ref $^{51}$ & Symmetry \\
\hline 105 & 115 & 102 & & 102 & 102 & 99 & $\mathrm{~A}_{g}$ \\
182 & 183 & 178 & 176 & 179 & 179 & 177 & $\mathrm{~A}_{g}$ \\
191 & 193 & 190 & 187 & 190 & 190 & 189 & $\mathrm{~A}_{g}$ \\
222 & 221 & 222 & 220 & 221 & 224 & 222 & $\mathrm{~B}_{g}$ \\
301 & 297 & 305 & 300 & 303 & 305 & 305 & $\mathrm{~A}_{g}$ \\
334 & $334\left(\mathrm{~A}_{g}\right)$ & 334 & 333 & 330 & 334 & 331 & $\mathrm{~B}_{g}$ \\
351 & & 348 & 344 & 343 & $348\left(\mathrm{~A}_{g}\right)$ & 343 & $\mathrm{~B}_{g}$ \\
386 & 392 & 382 & 380 & 378 & 381 & 376 & $\mathrm{~B}_{g}$ \\
478 & 476 & 476 & 475 & 475 & 476 & 473 & $\mathrm{~A}_{g}$ \\
509 & 500 & 500 & 510 & 504 & 505 & 498 & $\mathrm{~B}_{g}$ \\
538 & 534 & 534 & 536 & 539 & 536 & 534 & $\mathrm{~B}_{g}$ \\
562 & 554 & 556 & 558 & 561 & 556 & 557 & $\mathrm{~A}_{g}$ \\
619 & 605 & 615 & 613 & 618 & 616 & 613 & $\mathrm{~B}_{g}$ \\
629 & 625 & 637 & 635 & 640 & 637 & 633 & $\mathrm{~A}_{g}$ \\
& 726 & & 760 & 760 & 757 & 705 & $\mathrm{~A}_{g}$ \\
& & & & & & & \\
\hline
\end{tabular}

Tetragonal phase

\begin{tabular}{cccccccc}
\hline This study & $\boldsymbol{R e f}^{27}$ & Ref $^{28}$ & Ref $^{39}$ & Ref $^{43}$ & Ref $^{48}$ & Ref $^{52}$ & Symmetry \\
\hline 151 & $150\left(\mathrm{E}_{g}\right)$ & 148 & 163 & 145 & 147 & $146\left(\mathrm{E}_{g}\right)$ & $\mathrm{B}_{1 g}$ \\
263 & 260 & 266 & 273 & 268 & 269 & $270\left(\mathrm{~A}_{1 g}\right)$ & $\mathrm{E}_{g}$ \\
324 & 327 & 322 & 331 & 314 & 315 & 318 & $\mathrm{~B}_{1 g}$ \\
464 & 468 & 466 & 473 & 463 & 459 & 458 & $\mathrm{E}_{g}$ \\
602 & 609 & 609 & 610 & 604 & 600 & $602\left(\mathrm{~B}_{1 g}\right)$ & $\mathrm{A}_{1 g}$ \\
644 & $642\left(\mathrm{~B}_{1 g}\right)$ & 642 & 648 & 639 & 643 & 648 & $\mathrm{E}_{g}$
\end{tabular}

Cubic phase

\begin{tabular}{cccccccc}
\hline This study & Ref $^{30}$ & Ref $^{43}$ & Ref $^{44}$ & Ref $^{45}$ & Ref $^{46}$ & Ref $^{47}$ & Symmetry \\
\hline 617 & 607 & 616 & 600 & 618 & 640 & 600 & $F_{2 g}$ \\
\hline
\end{tabular}

Ref, reference number.

glass transition and temperature, and, therefore, the thermal residual stresses are generated during the cooling process. The minor extent of the $t \rightarrow m$ phase transformation observed in this study within the framework compared with the extent at the veneer-framework interface can be explained by the low concentration of stresses that are primarily responsible for this martensitic phase transformation. Swain ${ }^{16}$ derived the effect of thermal diffusivity on the creation of stresses. The highest temperature during the cooling process is maintained in the center of the body due to low thermal diffusivity. The external surface has the lowest temperature. ${ }^{16}$ The low thermal diffusivity of zirconia compared with the veneer material results in a high thermal gradient and leads to the buildup of residual stress at the veneer-zirconia interface ${ }^{16}$; this buildup is ultimately responsible for the larger extent of the $\mathrm{t} \rightarrow \mathrm{m}$ transformation observed at the interface in this study. Tholey et $\mathrm{al}^{23}$ explained the $t \rightarrow m$ phase transformation at the veneer-zirconia interface by the effect of the liquid required to produce veneering layers. Previous Raman studies did not reveal the presence of the phase transformation in the case of accelerated aging performed at a water-vapor pressure of $0.23 \mathrm{MPa}$ and a temperature of $134^{\circ} \mathrm{C}$ for zirconia sintered at $1350^{\circ} \mathrm{C} \cdot{ }^{37,38}$ Higher intensities of $\mathrm{m}$ peaks at the veneerframework interface for Y-TZP sintered at $1350^{\circ} \mathrm{C}$ can better be explained by the build-up of residual stresses created during the veneering process than by the occurrence of liquid at the interface. The extent of the $t \rightarrow m$ phase transformation observed along the veneerframework interface in this study was not homogeneous, which resulted in a heterogeneous stress distribution at the veneer-zirconia interface. The observation of this transformation for the nonfractured veneered copings can be explained by the diffusion of the veneer into the surface of zirconia during the firing processes, which results in a high stress concentration at the veneer-framework interface. Durand et $\mathrm{al}^{39,40}$ confirms this suggestion. In the case of nonfractured veneered copings, the temperature gradient factor is excluded. Perhaps the inhomogeneous phase transformation observed in this study can be better explained by inhomogeneous stresses created during the diffusion of liquid veneer into the framework surface than by coefficient of thermal expansion and the temperature gradients. Durand et $\mathrm{al}^{40}$ did not observe the $\mathrm{t} \rightarrow \mathrm{m}$ phase transformation. The $t$ and $m$ phases have Raman modes in the regions 466 to 478 and 620 to $640 \mathrm{~cm}^{-1}$. The 2 phases can be distinguished by the different intensity ratios of these modes. For the $\mathrm{m}$ phase, this ratio $\left(\mathrm{I}_{478} / \mathrm{I}_{629}\right)$ is higher than for the $t$ phase. It appears that Durand et $\mathrm{al}^{40}$ did not observe the $\mathrm{t} \rightarrow \mathrm{m}$ phase transformation in the zirconia core, but the increase of the peak ratio at the veneer-core interface observed in their study 

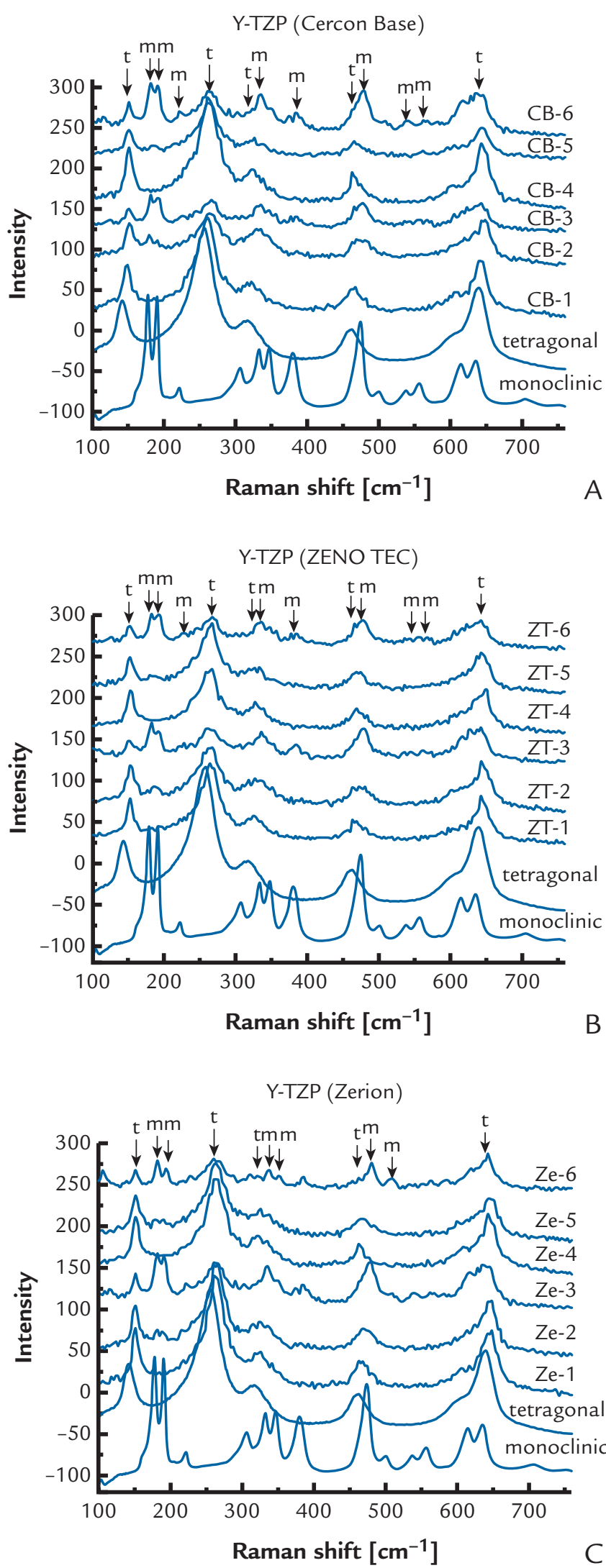

Raman spectra of coping subjected to different treatments. Labels of individual spectra correspond to groups specified in Table I. A, Cercon base and Cercon ceramic kiss were used for preparation of copings. B, ZENO TEC and Zirox were used for preparation of copings. C, Zerion and VITA M9 were used for preparation of copings. suggests that the researchers produced a phase transformation at the interface and that the core actually stayed intact. The lower volume fraction of the $\mathrm{m}$ phase observed for the $C B$ framework can be explained by the lower firing temperatures used for the preparation of the veneering ceramic, which resulted in a lower temperature gradient at the interface. In addition, a CB sintered at low temperature $\left(1350^{\circ} \mathrm{C}\right)$ has a smaller grain size than Y-TZP ceramics sintered at higher temperature, which results in a less-stressed structure. ${ }^{37,38}$ The $c$ phase of zirconia has only 1 active Raman mode, $\mathrm{F}_{2 g}$ at $616 \mathrm{~cm}^{-1}$. The occurrence of $\mathrm{m}\left(632 \mathrm{~cm}^{-1}\right)$ and $\mathrm{t}$ modes $\left(605\right.$ and $\left.644 \mathrm{~cm}^{-1}\right)$ in the same spectral region prevents detection of the $c$ phase. Thus, the presence of a small fraction of the $c$ phase in the specimens of groups 3 and 6 that exhibit a broad peak around $642 \mathrm{~cm}^{-1}$ cannot be excluded a priori. Pittayachawan et $\mathrm{al}^{41}$ identified the $\mathrm{c}$ phase in their specimens. According to these researchers, the $c$ phase has 3 active modes, 258, 466, and $628 \mathrm{~cm}^{-1}$. The calculations and the studies of the other researchers showed that the $c$ phase has only 1 active Raman mode. ${ }^{28,30,42-47}$ Oxygen vacancies are known to stabilize the $c$ and $t$ phases of zirconia at room temperature, but this is accompanied by structural disorder of the Y-TZP ceramic. The concentration of oxygen vacancies is higher for the $c$ phase, and, therefore, the Raman active mode of the $c$ phase is broader than that of the $t$ phase at $644 \mathrm{~cm}^{-1}$. The lack of a sharp peak for the $c$ phase thus can be explained by some disorder within the oxygen sublattice. ${ }^{46,47}$ The spectra of Pittayachawan et $\mathrm{al}^{41}$ centered at $637 \mathrm{~cm}^{-1}$ did not show this particular characteristic of the $c$ mode.

Future studies should concentrate on producing a veneer ceramic with a coefficient of thermal expansion closely matching that of zirconia to suppress the $t \rightarrow m$ phase transformation at the veneer-zirconia interface and improve the mechanical properties of ceramic dental restorations composed of a 
TABLE V. Calculated monoclinic volume fraction of monoclinic phase

\section{Specimens}

CB-1/ZT-1/Ze-1

CB-2/ZT-2/Ze-2

CB-3/ZT-3/Ze-3

CB-4/ZT-4/Ze-4

CB-5/ZT-5/Ze-5

CB-6/ZT-6/Ze-6

CB, Cercon base; ZT, ZENO TEC; Ze, Zerion.

Y-TZP ceramic framework and a porcelain veneer.

\section{CONCLUSIONS}

A considerable extent of $t \rightarrow m$ phase transformation was observed at the veneer-framework interface. The extent of the phase transformation depended on the distance from the veneer-framework interface. The intensity of the $m$ peaks in Raman spectra in the range 180 to $190 \mathrm{~cm}^{-1}$ decreased with increasing distance from this interface and was no longer observed at a distance greater than $20 \mu \mathrm{m}$. The extent of the $t \rightarrow m$ phase transformation along the veneer-framework interface was heterogeneous.

\section{REFERENCES}

1. Denry I, Kelly JR. State of the art of zirconia for dental applications. Dent Mater 2008;24: 299-307.

2. Kelly JR, Denry I. Stabilized zirconia as a structural ceramic: an overview. Dent Mater 2008;24:289-98.

3. Raigrodski A. Contemporary materials and technologies for all-ceramic fixed partial dentures: a review of the literature. J Prosthet Dent 2004;92:557-62.

4. Kern M. Resin bonding to oxide ceramics for dental restorations. J Adhes Sci Technol 2009;23:1097-111.

5. Blatz M, Sadan A, Kern M. Resin-ceramic bonding: a review of the literature. J Prosthet Dent 2003;89:268-74.

6. Chevalier J, Gremillard L, Virkar AV, Clarke DR. The tetragonal-monoclinic transformation in zirconia: lessons learned and future trends. J Am Ceram Soc 2009;92:1901-20.

7. Hisbergues M, Vendeville S, Vendeville P. Zirconia: established facts and perspectives for a biomaterial in dental implantology. J Biomed Mater Res Part B Appl Biomater 2009;88B:519-29.
8. Kosmac T, Oblak C, Jevnikar P, Funduk N, Marion L. The effect of surface grinding and sandblasting on flexural strength and reliability of Y-TZP zirconia ceramic. Dent Mater 1999;15:426-33.

9. Kosmac T, Oblak C, Marion L. The effect of dental grinding and sandblasting on ageing and fatigue behavior of dental (Y-TZP) ceramics. J Eur Ceram Soc 2008;28:1085-90.

10. Hallmann L, Ulmer P, Reusser E, Hämmerle C. Surface characterization of dental Y-TZP ceramic after air-abrasion treatment. J Dent 2012;40:723-35.

11. Hallmann L, Ulmer $P$, Reusser $E$, Hämmerle C. Effect of blasting pressure, abrasive particles size and grade on phase transformation and morphological change of dental zirconia surface. Surf Coat Technol 2012;206:4293-302.

12. Tang $X$, Nakamura $T$, Usami $H$, Wakabayashi K, Yatani H. Effects of multiple firings on the mechanical properties and microstructure of veneering ceramics for zirconia frameworks. J Dent 2012;40:372-80.

13. DeHoff PH, Barrett AA, Lee RB, Anusavice KJ Thermal compatibility of dental ceramic systems using cylindrical and spherical geometries. Dent Mater 2008;24:744-52.

14. Guazzato M, Proos K, Quach L, Swain MV. Strength, reliability and mode of fracture of bilayered porcelain/zirconia (Y-TZP) dental ceramics. Biomater 2004;25:5045-52.

15. Guess PC, Kulis A, Witkowski S, Wolkewitz M, Zhang Y, Strub JR. Shear bond strengths between different zirconia cores and veneering ceramics and their susceptibility to thermocycling. Dent Mater 2008;24:1556-67.

16. Swain MV. Unstable cracking (chipping) of veneering porcelain on all-ceramic dental crowns and fixed partial dentures. Acta Biomater 2009:5:1668-77.

17. Taskonak B, Borges GA, Mecholsky JJ, Anusavice KJ, Moore BK, Yan J. The effect of viscoelastic parameters on the residual stress development in a zirconia/glass bilayer dental ceramic. Dent Mater J 2008;24:1149-55.

18. Isgro G, Wang H, Kleverlaan CJ, Feilzer AJ. The effect of thermal mismatch and procedures on the deflection of layered allceramic discs. Dent Mater 2005;21:649-55.

19. Aboushelib MN, Feilzer AJ, Jager N, Kleverlaan CJ. Prestresses in bilayered allceramic restorations. J Biomed Mater Res Part B Appl Biomater 2008;87B:139-45.
20. Aboushelib MN, Kleverlaan CJ, Feilzer AJ. Effect of zirconia type on its bond strength with different veneer ceramics. J Prosthodont 2008;17:401-8

21. Aboushelib MN, Jager N, Kleverlaan CJ, Feilzer AJ. Microtensile bond strength of different components of core veneered allceramic restorations. Dent Mater 2005;21: 984-91.

22. Aboushelib MN, Kleverlaan CJ, Feilzer AJ. Microtensile bond strength of different components of core veneered allceramic restorations Part II: zirconia veneering ceramics. Dent Mater 2006;22: 857-63.

23. Tholey MJ, Berthold C, Swain MV, Thiel N $X R D^{2}$ micro-diffraction analysis of the interface between Y-TZP and veneering porcelain: role of the application methods. Dent Mater 2010;26:545-52.

24. Everall NJ. Modeling and measuring the effect of refraction on the depth resolution of confocal raman spectroscopy. Appl Spectrosc 2000;54:773-82.

25. Huy LD, Laffez P, Daniel P, Jouanneaux A, Khoi NT, Simeone D. Structure and phase component of $\mathrm{ZrO}_{2}$ thin films studied by raman spectroscopy and $\mathrm{X}$-ray diffraction. Mater Sci Eng B 2003;104:163-8.

26. Li M, Feng Z, Xiong G, Ying P, Xin Q, Li C. Phase transformation in the surface region of zirconia detected by UV raman spectroscopy. J Phys Chem B 2001;105:8107-11.

27. Lughi $V$, Clarke DR. Temperature dependence of the yttria-stabilized zirconia Raman spectrum. J Appl Phys 2007;101:053524053524-6.

28. Mirgorodsky AP, Smirnov MB, Quintard PE. Phonon spectra evolution and soft-mode instabilities of zirconia during the c-t-m transformation. J Phys Chem Solids 1999;60: 985-92.

29. Tabares JAM, Anglada MJ. Quantitative analysis of monoclinic phase in 3Y-TZP by raman spectroscopy. J Am Ceram Soc 2010;93:1790-5.

30. Hirata T, Asari E, Kitajima M. Infrared and raman spectroscopic studies of $\mathrm{ZrO}_{2}$ polymorphs doped with $\mathrm{Y}_{2} \mathrm{O}_{3}$ or $\mathrm{CeO}_{2}$. J Solid State Chem 1994;110:201-7.

31. Mainjot AK, Schajer GS, Vanheusden AJ, Sadoun MJ. Influence of veneer thickness on residual stress profile in veneering ceramic: measurement by hole-drilling. Dent Mater 2012;28:160-7.

32. Mainjot AK, Schajer GS, Vanheusden AJ, Sadoun MJ. Influence of zirconia thickness on residual stress profile in veneering ceramic: Measurement by hole-drilling. Dent Mater 2012:28:378-84.

33. Millen CS, Reuben RL, Ibbetson RJ. The effect of coping/veneer thickness on the fracture toughness and residual stress of implant supported, cement retained zirconia and metal-ceramic crowns. Dent Mater 2012;28. 250-8.

34. Zhang Z, Zhou S, Li Q, Li W, Swain M. Residual stresses in fabrication of core-veneered ceramic prostheses. Adv Mater Res 2010; 97-101:2241-4. 
35. Zhang Y, Allahkarami M, Hanan JC. Measuring residual stress in ceramic zirconiaporcelain dental crowns by nanoindentation. J Mech Behav Biomed Mater 2012;6:120-7.

36. Kim BK, Hahn JW, Han KR. Quantitative phase analysis in tetragonal-rich tetragonal/ monoclinic two phase zirconia by raman spectroscopy. J Mater Sci Lett 1997;16: 669-71.

37. Hallmann L, Mehl A, Ulmer P, Reusser E, Stadler J, Zenobi R, et al. The influence of grain size on low-temperature degradation of dental zirconia. J Biomed Mater Res Part B Appl Biomater 2012;100: 447-56.

38. Hallmann L, Ulmer P, Reusser E, Louvel M, Christoph HFH. Effect of dopants and sintering parameters on low temperature degradation of dental zirconia. J Eur Ceram Soc 2012;32:4091-4.

39. Durand J-C, Jacquot B, Salehi H, Margerit J, Cuisinier FJG. Confocal raman spectroscopy and SEM/EDS investigations of the interface between the zirconia core and veneering ceramic: the influence of a liner and generation firing. J Mater Sci Mater Med 2012;23: 1343-53.

40. Durand J-C, Jacquot B, Salehi H, Fages M, Margerit J, Cuisinier FJG. Confocal raman microscopic analysis of the zirconia/feldspathic ceramic interface. Dent Mater 2012;28:661-71.

41. Pittayachawan P, McDonald A, Young A, Knowles JC. Flexural strength, fatigue life, and stress-induced phase transformation study of Y-TZP dental Ceramic. J Biomed Mater Res Part B Appl Biomater 2007; 88B:366-77.
42. Feinberg A, Perry CH. Structural disorder and phase transitions in $\mathrm{ZrO}_{2}-\mathrm{Y}_{2} \mathrm{O}_{3}$ system. J Phys Chem Solids 1981;42:513-8.

43. Lopez EF, Escribano VS, Panizza M, Carnasciali MM, Busca G. Vibration and electronic spectroscopic properties of zirconia powders. J Mater Chem 2001;11:1891-7.

44. Cai J, Raptis C, Raptis YS, Anastassakis E. Temperature dependence of raman scattering in stabilized cubic zirconia. Phys Rev B Condens Matter 1995;51:201-9.

45. Pomfret MB, Stoltz C, Varughese B, Walker RA. Structural and compositional characterization of yttria-stabilized zirconia: evidence of surface-stabilized, low-valence metal species. Anal Chem 2005;77:1791-5.

46. Kontoyannia CG, Orkoula M. Quantitative determination of the cubic, tetragonal and monoclinic phases in partially stabilized zirconias by raman spectroscopy. J Mater Sci Lett 1994;29:5316-20.

47. Sekulic A, Furic K. Determination of the monoclinic, tetragonal and cubic phases in mechanically alloyed $\mathrm{ZrO}_{2}-\mathrm{Y}_{2} \mathrm{O}_{3}$ and $\mathrm{ZrO}_{2}-\mathrm{CoO}$ powder mixtures by raman spectroscopy. J Mater Sci Lett 1997;16:260-2.

48. Shi L, Tin K-C, Wong N-B. Thermal stability of zirconia membranes. J Mater Sci 1999;34: 3367-74.

49. Tkachev SN, Manghnani MN, Niilisk A, Aarik J, Mändar H. Micro-Raman spectroscopy and X-ray diffraction studies of atomiclayer-deposited $\mathrm{ZrO}_{2}$ and $\mathrm{HfO}_{2}$ thin films. J Mater Sci 2005;40:4293-8.

50. Quintard PE, Barberis P, Mirgorodsky AP, Mejean TM. Comparative lattice-dynamical study of the raman spectra of monoclinic and tetragonal phases of zirconia and hafnia. J Am Ceram Soc 2002;86:1745-9.
51. Carlone C. Raman spectra of zirconiahafnia mixed crystals. Phys Rev B 1992;45: 2079-84.

52. Merle T, Guinebretiere R, Mirgorodsky A, Quintard P. Polarized raman spectra of tetragonal pure $\mathrm{ZrO}_{2}$ measured on epitaxial films. Phys Rev B Condens Matter 2001;65: 144302-6.

Corresponding author:

Dr Lubica Hallmann

Department of Prosthodontics

Propaedeutics and Dental Materials

School of Dentistry

Christian-Albrechts University at Kiel

Arnold-Heller-Str.16

D-24105 Kiel

GERMANY

E-mail: Ihallmann@proth.uni-kiel.de

Acknowledgments

The authors thank Prof Ralf Spolenak, Barbara Grant, and Daniel Bernoulli (Laboratory of Nanometallurgy, ETH) for their technical help, and Dr Maxime Tchaya Njantio, application scientist (WITec $\mathrm{GmbH}$ ) for his appreciated advice. The vendors are thanked for the generous supplies of materials.

Copyright (C) 2014 by the Editorial Council for The Journal of Prosthetic Dentistry. 